\title{
Dental Trauma on whole Body Trauma CT_An underreported finding
}

\author{
Hans-Jonas Meyer ${ }^{1}\left[\right.$ Dominik Schramm ${ }^{2} \cdot$ Andreas Gunter Bach $^{2} \cdot$ Alexander Eckert $^{3} \cdot$ Alexey Surov $^{4}$
}

Received: 25 November 2020 / Accepted: 3 March 2021 / Published online: 15 March 2021

(c) The Author(s) 2021, corrected publication 2021

\begin{abstract}
Background The prevalence of dental injuries (DI) in polytrauma patients is unknown. The purpose of our study was to identify the frequency of dental injuries on whole body CTs acquired in a trauma setting and to estimate how often they are correctly reported by the radiologist.

Methods In the time period between 2006 and 2018 the radiological database of one university hospital was screened for whole-body trauma CTs. A total of 994 CTs were identified and re-evaluated.

Results Dental injuries were identified in 127 patients (12.8\% of patients). There were 27 women (21.3\%) and 100 men $(78.7 \%)$ with a mean age of $51.0 \pm 18.9$ years (range $10-96$ years). Regarding localization, most findings involved the molars $(n=107,37.4 \%)$, followed by the incisors $(n=81,28.3 \%)$, premolars $(n=59,20.6 \%)$ and canines $(n=39,13.7 \%)$. Most common findings were as follows: luxations $(n=49,45.8 \%)$, followed by crown fractures $(n=46,43 \%)$, root fractures $(n=10$, 9.3\%), extrusions $(n=1,0.9 \%)$, and intrusions $(n=1,0.9 \%)$. Only 15 findings ( $11.8 \%$ of all patients with dental injuries) were described in the original radiological reports.

Conclusion DI had a high occurrence in polytrauma patients. A high frequency of underreported dental trauma findings was identified. Radiologists reporting whole-body trauma CT should be aware of possible dental trauma to report the findings adequately.
\end{abstract}

Keywords Dental trauma $\cdot \mathrm{CT} \cdot$ Whole body CT

\section{Introduction}

Dental injury (DI) is after soft tissue injury one of the most common facial trauma occurrences. It can be found especially often in children and teenagers, most often involving

Hans-Jonas Meyer and Dominik Schramm authors contributed equally.

Hans-Jonas Meyer

Hans-jonas.meyer@medizin.uni-leipzig.de

1 Department of Diagnostic and Interventional Radiology, University of Leipzig, Leipzig, Germany

2 Diagnostic and Interventional Radiology, Martin-Luther-University Halle-Wittenberg, Halle (Saale), Germany

3 Department of Oral and Maxillofacial Surgery, Martin-Luther-University Halle-Wittenberg, Halle (Saale), Germany

4 Department of Radiology and Nuclear Medicine, Otto-von-Guericke University Magdeburg, Magdeburg, Germany the anterior region [1-3]. DI comprises crown and root fracture, luxation, intrusion, or avulsion [1]. In trauma patients with maxillofacial fractures, the incidence of DI is $13.1 \%$ [1]. In most cases, DI can be diagnosed based on clinical signs. Panoramic radiograph and cone-beam computed tomography (CT) are well-established imaging modalities to visualize DI $[4,5]$. Panoramic radiograph is the most used technique [4]. Cone-beam CT can be used to better visualize dental structures. These techniques can detect dental root fractures more reliably than multidetector CT, but they are not always easily available in the early assessment of the polytrauma patient [5-8].

Whole-body CT is a widely used imaging modality to identify injuries in multi-trauma patients $[9,10]$. The radiologist is challenged to view around 2000 pictures within a short time period and to correctly report pathological findings. At first, possibly lethal injuries need the full attention, such as intracranial hemorrhage, pneumothorax, vessel injuries, and bone fractures and afterwards the CT should be reassessed for other potential clinically relevant findings including dental findings [9]. Therefore, radiologists tend to 
overlook relevant findings of the teeth resulting in an overall underreporting of dental pathologies to the clinician [7, 8].

Previously, various studies reported non-traumatic clinically relevant incidental findings in whole body CTs [11-15]. These comprise cardiovascular findings, incidental malignant tumors, or inflammation foci [11-15]. However, no study systematically investigated dental injuries on whole-body trauma CT despite its potential common occurrence. Moreover, no study analyzed the frequency of sufficiently reported dental injuries.

Therefore, the aim of the present study was to identify the frequency of dental injuries on whole body CTs acquired in a trauma setting and to estimate how often they are correctly reported by the radiologist.

\section{Materials and methods}

This retrospective study was approved by the institutional ethics board (Martin-Luther University Halle-Wittenberg) and informed consent was waived.

In the time period between 2006 and 2018 the radiological database of one university hospital was screened for whole-body trauma CTs. All whole-body trauma CTs were analyzed within this time period. Isolated maxillofacial trauma patients were not considered in the present analysis.

The primary objective of this study was to estimate the frequency of dental trauma in a whole-body CT scan. As a next step, it was evaluated in the original radiology reports, whether these findings were reported or not by the radiologist.

We used a classification proposed by the World Health Organization comprising the following traumatic events: crown fracture, root fracture, avulsion, extrusion, intrusion, and luxation [3].

\section{Computed tomography}

Computed tomography (Somatom Sensation 64; Siemens, Erlangen, Germany and Toshiba Aquilion 64, Toshiba Medical Systems GmbH, Neuss, Germany) was performed in all patients. In all cases, $60-140 \mathrm{~mL}$ of iodinated intravenous contrast medium was given at a rate of $1.5-3.5 \mathrm{~mL} / \mathrm{s}$ by a power injector (Medtron $\mathrm{GmbH}$, Germany), with a scan delay of 30-90 s after the onset of injection. Typical imaging parameters were $120 \mathrm{kVp}, 150-300 \mathrm{mAs}$, and a slice thickness of $0.8 \mathrm{~mm}$ for the neck region with a pitch of 0.6.

\section{Image analysis}

All images were analyzed in digital format on a PACS workstation (Centricity PACS, GE Medical Systems, Milwaukee, Wisconsin, USA). Every CT scan was again re-analyzed by one radiologist with 7 years of general experience to identify possible dental trauma findings blinded to the clinical and radiology reports. The images were evaluated using 3-dimensional reconstructions. In unclear cases, a consensus was made with a consultant radiologist with 17 years of experience.

\section{Statistical analysis}

Statistical analysis was performed using GraphPad Prism 5 (GraphPad Software, La Jolla, CA). Collected data were evaluated by means of descriptive statistics. Continuous variables were expressed as mean \pm standard deviation and categorical variables as percentages. Fisher's exact test was used to test between groups.

\section{Results}

A total of 994 patients/CTs were identified and re-evaluated. Overall, dental trauma injuries occurred in 127 patients (12.8\% of all trauma patients) (Figs. 1, 2).

There were 27 women $(21.3 \%$ ) and 100 men (78.7\%) with a mean age of $51.0 \pm 18.9$ years (range $10-96$ years). One tooth was injured in 32 cases (41.6\%), 2 to 5 teeth were injured in 31 cases (40.1\%), and over five teeth were injured in 14 patients (18.2\%). Overall, 286 injuries were identified. Furthermore, 41 patients (32.3\%) were intubated, and 86 patients $(67.7 \%)$ were not. In 7 patients (5.5\%), an associated bone fracture of the facial region was identified. Regarding localization, most findings involved the molars $(n=107$, $37.4 \%)$, followed by incisors $(n=81,28.3 \%)$, premolars $(n=59,20.6 \%)$ and canine $(n=39,13.7 \%)$ (Table 1).

Most common findings were dental luxation $(n=49$, $45.8 \%)$, followed by crown fractures $(n=46,43.0 \%)$, root fractures $(n=10,9.3 \%)$, extrusions ( $n=1,0.9 \%)$, and intrusions $(n=1,0.9 \%)$. There were no displaced tooth fragments identified within the aerodigestive tract.

Only 15 findings $(11.8 \%$ of all patients with dental injuries) were identified in the original radiology report (Table 2).

In the group with correctly reported findings, six patients suffered from an associated facial bone fracture (40\%), whereas in the non-reported group only one patient suffered from a fracture $(0.9 \%)$, which is a significantly different ratio $(p<0.001)$.

\section{Discussion}

The present study identified a high frequency of DI. Overall, DI occurred in $12.8 \%$ of all polytrauma cases. Furthermore, only $11.8 \%$ of these were sufficiently described in the original radiology reports. 

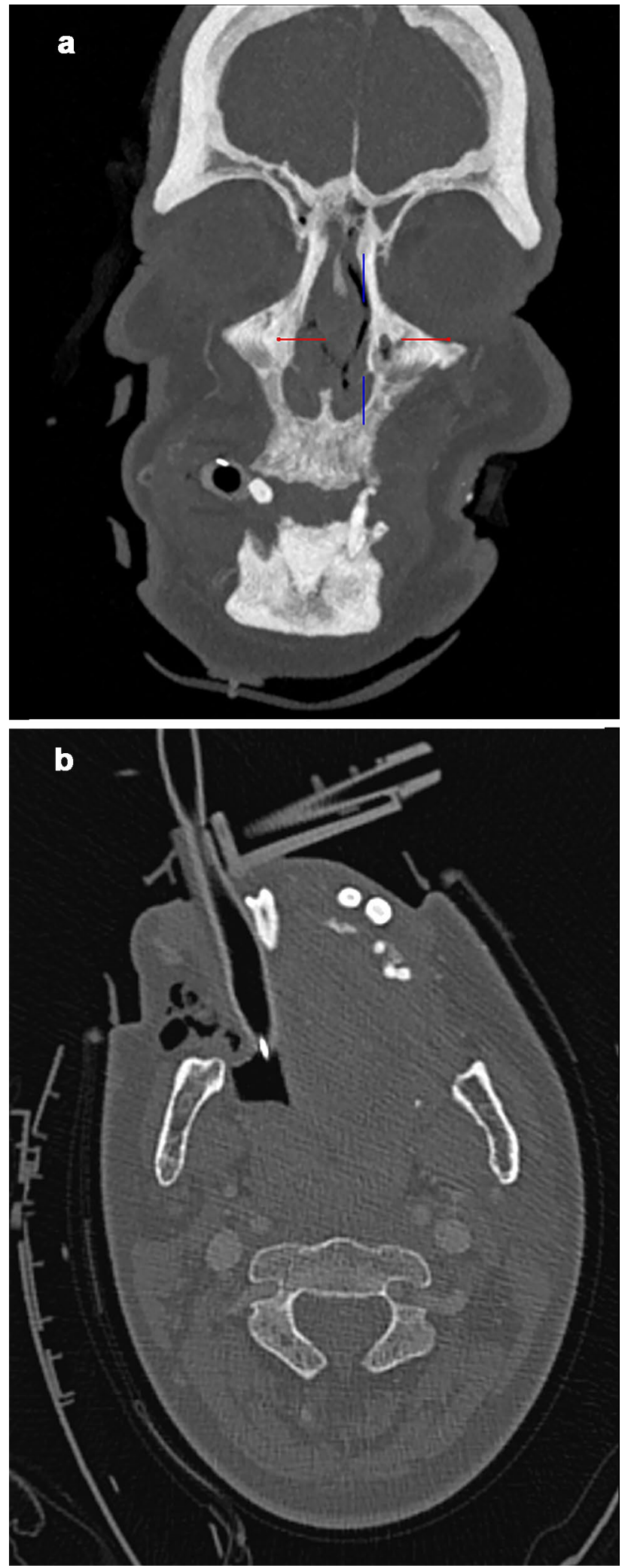

Fig. 1 a Maximum intensity projection in the coronal plane of a 64-years old male patient. Avulsion of the right lower incisor with an associated non-displaced fracture of the mandible. The tooth is directly adjacent to the tube. b Axial plane. The finding was correctly reported by the radiologist
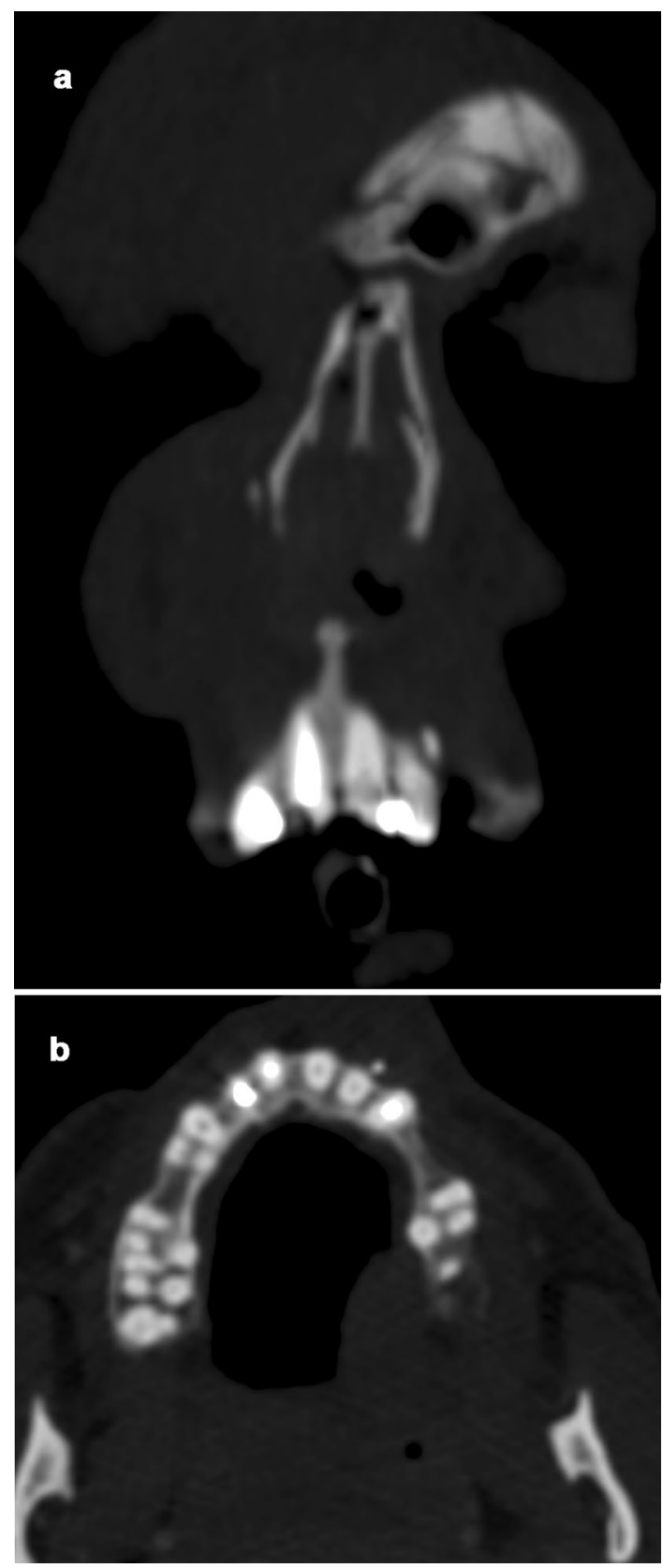

Fig. 2 a Maximum intensity projection in the coronal plane of a 21-years old male patient. Root fracture of the left upper incisor. The patient suffered from a complex fracture of the skull, yet no direct adjacent fracture to the tooth. This dental finding was not reported by the radiologist. b The tooth fragment can also be appreciated in the axial plane

The prevalence of DI in a clinical trauma setting is still unknown. In fact, clinical dental investigations showed that the prevalence of dental trauma ranged significantly, namely from 6 to 59\% [16]. Furthermore, in a meta-analysis, a prevalence of dental trauma was up to $5 \%$ of all trauma findings [17]. However, no study analyzed the frequency of dental injuries on whole-body CT in trauma patients. 
Table 1 Overview about the dental trauma findings identified in all patients

\begin{tabular}{llllll}
\hline Type of finding & Incisor & Canine & Premolar & Molarn & Total \\
\hline Crown fracture & 28 & 10 & 22 & 46 & 106 \\
Root fracture & 8 & 7 & 6 & 10 & 31 \\
Avulsion & 0 & 0 & 0 & 0 & 0 \\
Extrusion & 1 & 1 & 1 & 1 & 4 \\
IntrusionIntrusion & 0 & 0 & 0 & 1 & 1 \\
Luxation & 44 & 21 & 30 & 49 & 144 \\
Total & 81 & 39 & 59 & 107 & \\
\hline
\end{tabular}

Table 2 Dental trauma findings, which were correctly reported by the radiologist

\begin{tabular}{llllll}
\hline Type of finding & Incisor & Canine & Premolar & Molarn & Total \\
\hline Crown fracture & 3 & 2 & 2 & 4 & 11 \\
Root fracture & 1 & 5 & 3 & 2 & 11 \\
Avulsion & 0 & 0 & 0 & 0 & 0 \\
Extrusion & 0 & 1 & 1 & 1 & 3 \\
Intrusion & 0 & 0 & 0 & 0 & 0 \\
Luxation & 6 & 9 & 4 & 4 & 23 \\
Total & 10 & 17 & 10 & 11 & \\
\hline
\end{tabular}

It is not unusual that whole-body CT can detect numerous findings of the body with a high accuracy, comprising non-trauma-related incidental findings and possible hazardous trauma findings [10-14]. However, some dental findings might not be detectable by multidetector CT due to only subtle fracture lines [8]. This is a reason why cone-beam CT has a slight superior accuracy compared to multidetector $\mathrm{CT}$ and may detect more trauma findings [18].

Another reason for possible misdiagnosis of DI on wholebody CT can be image artifacts, especially scatter artifacts caused by dental amalgam. These artifacts are a common problem and can obscure the anatomy and potential pathological findings of the oral cavity [19]. Therefore, the frequency of dental injuries might be even higher than reported in this study.

Notably, the radiologist is faced to evaluate numerous images in a small timeframe to make correct diagnoses. In the trauma setting, possible life-threatening conditions must be diagnosed immediately before other imaging findings, including dental-related findings, can be addressed. Then, roughly $40 \%$ of patients undergoing a whole-body CT, show additionally at least one incidental finding $[11,12,20]$.

This might also be a reason that a lot of findings are not sufficiently reported by the radiologist. For chest CTs, it was acknowledged that only $55 \%$ of easily detectable cardiac findings were reported within the radiologist report [21].
Similar results were reported for cardiovascular findings on whole-body CT [14].

In a recent retrospective study, Bulbul et al. reported that dental findings are frequent findings on CT performed to evaluate paranasal sinus [7]. In fact, $51 \%$ of patients had a pathological finding, most commonly carious lesions in $27 \%$ of cases [7]. In another study examining different head CT scans, it has been shown that dental diseases were significantly underreported with only $11 \%$ of sufficient mentions in the radiology report [22]. We identified that dental findings were significantly more reported when DI was associated with a bone fracture. Presumably, the radiologist is more concerned for bone fracture assessment and the fracture leads the radiologist to the dental trauma finding. In short, one key finding of the present study is that dental trauma findings are severely under-reported by radiologists in acute clinical situations.

Unlike dental trauma involving only teeth, which is managed by a dentist in an outpatient clinic, dental trauma associated with polytrauma is managed in a hospital setting [1]. This might also be a reason why the radiologists at a tertiary hospital tends to overlook findings of the teeth. Another reason might be that dental findings tend to be very subtle, easily to be overlooked [8]. Most of the reported findings were severe trauma findings associated with adjacent bone fractures. These findings might be easily detectable and, thus, were reported by the radiologists. Moreover, there might be not enough clinical information regarding trauma mechanism and possible damage of the teeth. Of note, many dental trauma findings can be diagnosed by a clinical examination, except of root fractures, which can only be diagnosed by imaging.

It should be considered that dental trauma may be caused by the initial trauma or may be iatrogenic especially after endotracheal intubation [23, 24]. It was identified that existing dental anomalies increases the risk for dental injury by endotracheal intubation in a 12-fold manner [24]. So far, in a study investigating 3423 emergency endotracheal intubations, only 6 dental injuries ( $0.2 \%$ of all patients) were identified. This finding indicates that the dental injuries detected in the present study were most commonly caused by the trauma itself [24].

On the other hand, dental injuries might complicate the acute treatment itself, especially the endotracheal intubation [25]. Moreover, they could acutely compromise the airway and may lead to aspiration, albeit no systematical data exists investigating such complications. So, a recent case report highlighted the importance of imaging modalities to correctly identify these aspirated tooth fragments [26]. In our patient sample no aspirated tooth fragments were identified, which nevertheless diminished the importance of these findings. 
Interestingly, our results are in agreement with a recent epidemiological study, which identified a comparable prevalence $(13 \%)$ of dental traumas [27]. However, the present results might be different in comparison to those based on clinical examination in patients with isolated dental injuries [28, 29].

There are several important factors for the etiology of dental injuries. Overjet was significantly associated with dental injuries in every dentition and age groups [30]. Moreover, orthodontic treatment is associated with dental injuries in children [31]. In adults, there is a moderate evidence that alcohol use is associated with DI [32]. Previous occurrence of dental injuries is also a risk factor for another one [33].

In summary, the correct diagnosis of dental trauma can be important for the patient and for possible treatment planning. Although not every dental trauma is treated, the cost of dental trauma is high and often time consuming [17].

Our study emphasizes that radiologists need to pay more attention to findings of the teeth in trauma patients due to its high frequency.

There are some limitations of the present study to address. First, it is a retrospective study with possible inherent bias. However, the CTs were evaluated without clinical information and blinded to the radiological and clinical reports to reduce possible bias. Second, the reporting rate is specific for one university hospital. There might be institutions, in which dental trauma findings are reported more frequently. Thirdly, there might be a bias of preexisting dental injuries, which were included in the present analysis as the exact age of dental trauma findings cannot be determined with the CT. Fourthly, the real frequency of dental trauma findings might be even higher due to missed findings on CT.

\section{Conclusion}

DI had a high occurrence in polytrauma patients. A high frequency of underreported dental trauma findings was identified. The radiologists should be aware of possible dental trauma on whole-body trauma CT to sufficiently report these findings.

\section{Author contributions conceptualization}

AS and HJM; methodology: HJM and DS; formal analysis and investigation: $\mathrm{HJM}, \mathrm{DS}, \mathrm{AB}, \mathrm{AE}$; writing-original draft preparation: HJM writing-review and editing: AS; supervision: AS.

Acknowledgements None.
Funding Open Access funding enabled and organized by Projekt DEAL.

\section{Declarations}

Conflict of interest None.

Ethical approval Institutional review board University of Halle (Saale).

Patient consent Not required.

Open Access This article is licensed under a Creative Commons Attribution 4.0 International License, which permits use, sharing, adaptation, distribution and reproduction in any medium or format, as long as you give appropriate credit to the original author(s) and the source, provide a link to the Creative Commons licence, and indicate if changes were made. The images or other third party material in this article are included in the article's Creative Commons licence, unless indicated otherwise in a credit line to the material. If material is not included in the article's Creative Commons licence and your intended use is not permitted by statutory regulation or exceeds the permitted use, you will need to obtain permission directly from the copyright holder. To view a copy of this licence, visit http://creativecommons.org/licenses/by/4.0/.

\section{References}

1. Roccia F, Boffano P, Bianchi FA, Ramieri G. An 11-year review of dental injuries associated with maxillofacial fractures in Turin. Italy Oral Maxillofac Surg. 2013;17(4):269-74. https://doi.org/10. 1007/s10006-012-0371-4.

2. Borssen E, Holm AK. Traumatic dental injuries in a cohort of 16-year-olds in northern Sweden. Endod Dent Traumatol. 1997;13(6):276-80. https://doi.org/10.1111/j.1600-9657.1997. tb00055.x.

3. Bastone EB, Freer TJ, McNamara JR. Epidemiology of dental trauma: a review of the literature. Aust Dent J. 2000;45(1):2-9. https://doi.org/10.1111/j.1834-7819.2000.tb00234.x.

4. Sklavos A, Beteramia D, Delpachitra SN, Kumar R. The panoramic dental radiograph for emergency physicians. Emerg Med J. 2019;36(9):565-71. https://doi.org/10.1136/emerm ed-2018-208332.

5. Gao A, Cao D, Lin Z. Diagnosis of cracked teeth using cone-beam computed tomography: Literature review and clinical experience. Dentomaxillofac Radiol. 2020. https://doi.org/10.1259/dmfr. 20200407.

6. Al Hadi D, Parekh S, Naeem W, Luke AM, Mathew S. Detection of vertical root fractures using three different imaging modalities: An In Vitro Study. J Contemp Dent Pract. 2020;21(5):549-53.

7. Bulbul E, Yanik B, Demirpolat G. Detection of dental pathologies in routine paranasal CT scans: a retrospective study. J Clin Diagn Res. 2017;11(7):TC17-20. https://doi.org/10.7860/JCDR/2017/ 27461.10287

8. Scheinfeld MH, Shifteh K, Avery LL, Dym H, Dym RJ. Teeth: what radiologists should know. Radiographics. 2012;32(7):192744. https://doi.org/10.1148/rg.327125717.

9. Linsenmaier U, Geyer LL, Körner M, Reiser M, Wirth S. Importance of multidetector CT imaging in multiple trauma. Radiologe. 2014;54(9):861-71. https://doi.org/10.1007/s00117-013-2634-y. 
10. Yoong S, Kothari R, Brooks A. Assessment of sensitivity of whole body CT for major trauma. Eur J Trauma Emerg Surg. 2019;45(3):489-92. https://doi.org/10.1007/s00068-018-0926-7.

11. Kroczek EK, Wieners G, Steffen I, Lindner T, Streitparth F, Hamm B, Maurer MH. Non-traumatic incidental findings in patients undergoing whole-body computed tomography at initial emergency admission. Emerg Med J. 2017;34(10):643-6. https:// doi.org/10.1136/emermed-2016-205722.

12. Fakler JKM, Ozkurtul O, Josten C. Retrospective analysis of incidental non-trauma associated findings in severely injured patients identified by whole-body spiral CT scans. Patient Saf Surg. 2014;2014(8):36. https://doi.org/10.1186/s13037-014-0036-3.

13. Seah MK, Murphy CG, McDonald S, Carrothers A. Incidental findings on whole-body trauma computed tomography: Experience at a major trauma centre. Injury. 2016;47(3):691-4. https:// doi.org/10.1016/j.injury.2016.01.012.

14. Meyer HJ, Schramm D, Bach AG, Beeskow A, Surov A. Cardiovascular findings on computed tomography in patients with unclear finding situation and trauma of unknown origin. Medicine (Baltimore). 2017;96(42):e8263. https://doi.org/10.1097/MD. 0000000000008263.

15. Lumbreras B, Donat L, Hernández-Aguado I. Incidental findings in imaging diagnostic tests: a systematic review. Br J Radiol. 2010;83(988):276-89. https://doi.org/10.1259/bjr/98067945.

16. Lam R. Epidemiology and outcomes of traumatic dental injuries: a review of the literature. Aust Dent J. 2016;61(Suppl 1):4-20. https://doi.org/10.1111/adj.12395.

17. Zaleckiene V, Peciuliene V, Brukiene V, Drukteinis S. Traumatic dental injuries: etiology, prevalence and possible outcomes. Stomatologija. 2014;16(1):7-14.

18. Li F, Li J, Zhang D, Wu F. Role of computed tomography scan in dental trauma: a cross-sectional study. Dose Response. 2018;16(3):1559325818789837. https://doi.org/10.1177/15593 25818789837.

19. Diehn FE, Michalak GJ, DeLone DR, Kotsenas AL, Lindell EP, Campeau NG, Halaweish AF, McCollough CH, Fletcher JG. CT Dental artifact: comparison of an iterative metal artifact reduction technique with weighted filtered back-projection. Acta Radiol Open. 2017;6(11):2058460117743279. https://doi.org/10.1177/ 2058460117743279.

20. Andrawes P, Picon AI, Shariff MA, Azab B, von Waagner W, Demissie S, Fasanya C. CT scan incidental findings in trauma patients: does it impact hospital length of stay? Trauma Surg Acute Care Open. 2017;2(1):e000101. https://doi.org/10.1136/ tsaco-2017-000101.

21. Sverzellati N, Arcadi T, Salvolini L, Dore R, Zompatori M, Mereu M, Battista G, Martella I, Toni F, Cardinale L, Maffei E, Maggi F, Cademartiri F, Pirronti T. Under-reporting of cardiovascular findings on chest CT. Radiol Med. 2016;121(3):190-9. https:// doi.org/10.1007/s11547-015-0595-0.
22. Hammoud K, Lanfranchi M, Adams D, Bedi HS, Mehan WA. Prevalence and Reporting Rates of Incidental Dental Disease on Head CT Examinations. Acad Radiol. 2018;25(10):1318-24. https://doi.org/10.1016/j.acra.2018.01.017.

23. Tan Y, Loganathan N, Thinn KK, Liu EHC, Loh NW. Dental injury in anaesthesia: a tertiary hospital's experience. BMC Anesthesiol. 2018;18(1):108. https://doi.org/10.1186/ s12871-018-0569-6.

24. Martin LD, Mhyre JM, Shanks AM, Tremper KK, Kheterpal S. 3,423 emergency tracheal intubations at a university hospital: airway outcomes and complications. Anesthesiology. 2011;114(1):42-8. https://doi.org/10.1097/ALN.0b013e3182 $01 \mathrm{c} 415$.

25. Yasny JS. Perioperative dental considerations for the anesthesiologist. Anesth Analg. 2009;108(5):1564-73. https://doi.org/10. 1213/ane.0b013e31819d1db5.

26. Ramarai PN, Mahabaleshwara CH, Singh R, George A, Vijayalakshmi G. Missing teeth after maxillofacial trauma: a case report and management protocol. J Korean Assoc Oral Maxillofac Surg. 2020;46(6):422-7. https://doi.org/10.5125/jkaoms.2020.46.6.422.

27. Tewari N, Mathur VP, Siddiqui I, Morankar R, Verma AR, Pandey RM. Prevalence of traumatic dental injuries in India: A systematic review and meta-analysis. Indian J Dent Res. 2020;31(4):601-14. https://doi.org/10.4103/ijdr.IJDR_953_19.

28. Tan YZ, Levin L, Guo W, Chen Y. Dental injuries at the Xi'an, China stomatological hospital: a retrospective study. Dent Traumatol. 2020;36(5):505-9. https://doi.org/10.1111/edt.12572.

29. Faus-Matoses V, Faus-Matoses I, Ruiz-Sánchez C, Faus-Damiá M, Faus-Llácer VJ. Incidence of traumatic dental injury in Valencia, Spain. Med Oral Patol Oral Cir Bucal. 2020;25(5):e592-8. https://doi.org/10.4317/medoral.23630.

30. Arraj GP, Rossi-Fedele G, Doğramacı EJ. The association of overjet size and traumatic dental injuries-A systematic review and meta-analysis. Dent Traumatol. 2019;35(4-5):217-32. https://doi. org/10.1111/edt.12481.

31. Borzabadi-Farahani A, Borzabadi-Farahani A. The association between orthodontic treatment need and maxillary incisor trauma, a retrospective clinical study. Oral Surg Oral Med Oral Pathol Oral Radiol Endod. 2011;112(6):e75-80. https://doi.org/10.1016/j.tripl eo.2011.05.024.

32. Baraúna Magno M, de França Leite KL, Melo Pithon M, Maia LC. Are traumatic dental injuries greater in alcohol or illicit drugs consumers? A systematic review and meta-analysis. Drug Alcohol Depend. 2019;2019(197):236-49. https://doi.org/10.1016/j.druga lcdep.2018.12.028.

33. Magno MB, Neves AB, Ferreira DM, Pithon MM, Maia LC. The relationship of previous dental trauma with new cases of dental trauma. A systematic review and meta-analysis. Dent Traumatol. 2019;35(1):3-14. https://doi.org/10.1111/edt.12449. 